\title{
Evaluation of an Oxygen Mask-Based Capnometry Device in Subjects Extubated After Abdominal Surgery
}

\author{
Shunsuke Takaki MD PhD, Takahiro Mihara MD PhD, Kenji Mizutani MD, \\ Osamu Yamaguchi MD PhD, and Takahisa Goto MD PhD
}

\begin{abstract}
BACKGROUND: For early detection of respiratory and hemodynamic changes during anesthesia, continuous end-tidal carbon dioxide concentration $\left(\mathbf{P}_{\mathrm{ETCO}_{2}}\right)$ is monitored by capnometry. However, the accuracy of $\mathrm{CO}_{2}$ monitoring during spontaneous breathing in extubated patients remains undetermined. Therefore, we aimed to compare $P_{\text {ETCO, }}$ measured by capnometry using an oxygen mask with a carbon dioxide sampling port (capnometry-type oxygen mask) and $\mathbf{P}_{\mathbf{C O}}$ in extubated subjects who had undergone abdominal surgery. Furthermore, we investigated whether spontaneous deep breathing affected dissociation between $\mathbf{P}_{\mathrm{aCO}_{2}}$ and $\mathbf{P}_{\mathrm{ETCO}}$. METHODS: Adult post-abdominal surgery subjects admitted to the ICU were enrolled in this study. After extubation, oxygen was supplied at $6 \mathrm{~L} / \mathrm{min}$ using the capnometry-type oxygen mask. After $30 \mathrm{~min}$ of oxygen supply, $\mathbf{P}_{\mathrm{aCO}}$ blood gas analysis was performed, and $\mathbf{P}_{\mathrm{ETCO}_{2}}$ was measured under resting and deep-breathing conditions. For both resting and deep-breathing conditions, the correlation between $\mathbf{P}_{\mathrm{aCO}}$ and $\mathbf{P}_{\text {ETCO}_{2}}$ was analyzed. Furthermore, bias, precision, and limits of agreement were calculated using the Bland-Altman method. RESULTS: Twenty-five subjects (15 men, 10 women) with a mean age of $62 \mathrm{y}$ (interquartile range of $57-76 \mathrm{y}$ ) and body mass index of $20-24 \mathrm{~kg} / \mathrm{m}^{2}$ were studied. The correlation ( $r$ ) between $\mathrm{P}_{\mathrm{aCO}}$ and $\mathrm{P}_{\mathrm{ETCO}}$ under resting and deep-breathing conditions was 0.50 and 0.56, respectively. Compared with $P_{a C O}$, the bias and limits of agreement were $-12.6(-20.6$ to -4.6) for resting $P_{\mathrm{ETCO}_{2}}$ and $\mathbf{- 9 . 1}(-\mathbf{1 6 . 0}$ to -2.1$)$ for deep-breathing $\mathbf{P}_{\mathrm{ETCO}_{2}}$. The association between $\mathbf{P}_{\mathrm{aCO}_{2}}$ and deep-breathing $\mathbf{P}_{\mathrm{ETCO}_{2}}$ was significantly smaller compared with resting $\mathbf{P}_{\mathrm{ETCO}_{2}}$ $(P=.002)$. CONCLUSIONS: It is possible to measure the $P_{\mathrm{ETCO}_{2}}$ under varying breathing conditions with the capnometry-type oxygen mask in subjects receiving oxygen supplementation after extubation following upper abdominal surgery to determine whether they are properly ventilating. (ClinicalTrials.gov registration UMIN000011925.) Key words: capnometry; end-tidal carbon dioxide; postoperative monitoring; ventilation/perfusion mismatch. [Respir Care 2015;60(5):705-710. (C) 2015 Daedalus Enterprises]
\end{abstract}

\section{Introduction}

Compared with other surgeries, the incidence of pulmonary complications is higher after upper abdominal or chest surgery because both surgeries involve severe and

Drs Takaki, Mizutani, Yamaguchi, and Goto are affiliated with the Department of Anesthesiology and Intensive Care Unit, Yokohama City University Hospital, Kanagawa, Japan. Dr Mihara is affiliated with the Department of Anesthesiology, Kanagawa Children's Medical Center, Kanagawa, Japan

The study was supported by the Yokohama City University Hospital. The authors have disclosed no conflicts of interest. prolonged alteration of pulmonary mechanics. ${ }^{1}$ After abdominal operations, active collapse of the lungs along with hypoventilation is the major cause of postoperative hypoxia and pulmonary complications. ${ }^{2,3}$ Furthermore, surgical trauma after thoracic and abdominal surgery affects respiratory muscles, leading to postoperative hypoxia and

\footnotetext{
Correspondence: Shunsuke Takaki MD PhD, Department of Anesthesiology and Intensive Care Unit, Yokohama City University Hospital, 3-9 Fukuura, Kanazawa-ku, Yokohama city, Kanagawa 236-0004, Japan. E-mail: shunty5323@gmail.com.
}

DOI: $10.4187 /$ respcare. 03557 


\section{Oxygen Mask-Based Capnometry Device After Extubation}

pulmonary complications. ${ }^{4}$ Three factors produce respiratory muscle dysfunction after abdominal surgery. First, muscle disruption by surgical incision impairs effectiveness of respiratory muscles. Second, postoperative pain may cause voluntary limitation of respiratory motion. Third, surgical trauma stimulates central nervous system reflexes mediated by both visceral and somatic nerves that produce reflex inhibition of the phrenic and other nerves, innervating respiratory muscles. ${ }^{4}$ Therefore, monitoring respiratory function in patients who have undergone abdominal surgery is one of the essential assessments carried out in ICUs.

Capnography is an increasingly popular procedure; its widespread clinical use may improve patient care and safety. Assessment of the extrapolated end-tidal carbon dioxide concentration $\left(\mathrm{P}_{\mathrm{ETCO}}\right)$ is one of the most useful aspects of capnography. ${ }^{5}$ The levels of alveolar $\left(\mathrm{P}_{\mathrm{ETCO}_{2}}\right)$ and arterial $\left(\mathrm{P}_{\mathrm{aCO}}\right) \mathrm{CO}_{2}$ are similar in healthy subjects (eg, difference of $<5 \mathrm{~mm} \mathrm{Hg}$ ). Therefore, in subjects with normal dead space, it is safe to use $\mathrm{P}_{\mathrm{ETCO}}$ as a substitute for $\mathrm{P}_{\mathrm{aCO}}{ }^{6-8}$ However, in patients who have undergone abdominal surgery, the levels of alveolar and arterial $\mathrm{CO}_{2}$ are altered due to changes in respiratory and hemodynamic conditions.

Physiological dead space is the sum of anatomical and alveolar dead space and is defined as the sum of all parts of the tidal volume that do not participate in gas exchange. ${ }^{9}$ In healthy subjects, physiological dead space is small and inconsiderable; however, in postoperative patients, respiratory mechanics are altered, and several changes lead to increased physiological dead space. The functional residual capacity continuously decreases after an operation, usually reaching its lowest value 1-2 d after the operation, before slowly returning to normal values within 1 week. ${ }^{10}$

The most common problem during surgery is ventilation/perfusion mismatching that leads to impaired gas exchange, which persists during the postoperative period. The $\mathrm{P}_{\mathrm{ETCO}}$ is continuously monitored by capnometry for early detection of respiratory or hemodynamic changes during anesthesia. However, in extubated patients, $\mathrm{P}_{\mathrm{ETCO}_{2}}$ monitoring requires a device that can draw a continuous gas sample for spectrographic measurements with the capnometer. ${ }^{11-13}$ Furthermore, the $\mathrm{P}_{\mathrm{ETCO}_{2}}$ wave is normally unstable in non-intubated patients because the oxygen supply system is not closed compared with the oxygen system with mechanical ventilation using an endotracheal tube during anesthesia.

The newly developed capnometry-type oxygen mask (Japan Medical Next, Tokyo, Japan) has a $\mathrm{P}_{\mathrm{ETCO}_{2}}$ sampling line for use in spontaneously breathing patients (Fig. 1). Previous studies have shown that this device is useful for monitoring respiration in extubated subjects. ${ }^{14,15}$ However, dissociation between $\mathrm{P}_{\mathrm{ETCO}_{2}}$ and $\mathrm{P}_{\mathrm{aCO}}$ has not

\section{QUICK LOOK}

\section{Current knowledge}

End-tidal carbon dioxide concentration monitoring with capnometry in anesthesia is a standard of care. Capnometry assures appropriate airway position and provides early detection of changes in ventilation and perfusion. The accuracy of carbon dioxide monitoring during spontaneous breathing in extubated patients receiving oxygen therapy is less reliable.

\section{What this paper contributes to our knowledge}

A simple mask modified to allow sidestream sampling of gases was able to reliably monitor expired carbon dioxide in a group of postoperative subjects. The system was effective across a range of breathing patterns during oxygen delivery.

been investigated, and the precision of $\mathrm{CO}_{2}$ monitoring by oxygen mask capnometry remains unclear.

The purpose of this study was to compare $\mathrm{P}_{\mathrm{ETCO}_{2}}$ measured by capnometry using the capnometry-type oxygen mask with $\mathrm{P}_{\mathrm{aCO}_{2}}$ obtained by blood gas analysis. The secondary goal was to evaluate the association between $\mathrm{P}_{\mathrm{aCO}}$ and $\mathrm{P}_{\mathrm{ETCO}_{2}}$ under different breathing conditions. Because functional residual capacity is frequently reduced in patients undergoing surgery near the diaphragm (ie, upper abdominal or thoracic incisions), ${ }^{16}$ we assessed whether deep breathing that decreases the physiological dead space leads to dissociation between $\mathrm{P}_{\mathrm{ETCO}_{2}}$ and $\mathrm{P}_{\mathrm{aCO}_{2}}$.

\section{Methods}

This prospective study was conducted at the Yokohama City University Hospital, a teaching hospital in Japan. The ethics committee of the Yokohama City University Hospital approved the design of this study. This study was registered with the University Hospital Medical Information Network Center (UMIN000011925), and informed consent was obtained from all subjects. For this study, adult subjects admitted to the ICU after extubation in the operating room for an abdominal operation were included. These subjects were monitored in the ICU for preventive postoperative complications, such as bleeding, respiratory dysfunction, and hemodynamic instability. The exclusion criteria were: $<18$ y old, inability to maintain an $\mathrm{S}_{\mathrm{pO}_{2}}$ of $>95 \%$ with an oxygen mask, need for noninvasive mechanical ventilation, body mass index of $>30 \mathrm{~kg} / \mathrm{m}^{2}$, and absence of epidural anesthesia because conditions such as obesity and surgical trauma pain probably influence postoperative respiratory function, leading to ventilation-per- 


\section{Oxygen Mask-Based Capnometry Device After Extubation}

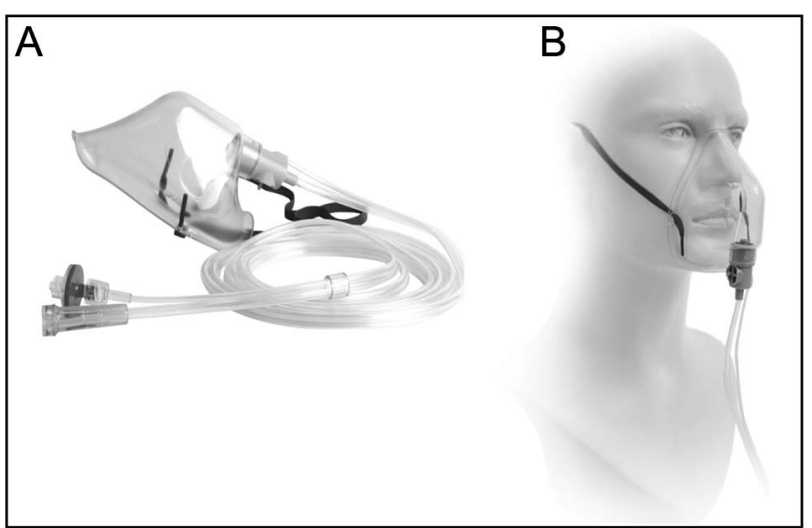

Fig. 1. A: Capnometry-type oxygen mask. This mask has a $\mathrm{CO}_{2}$ sampling port next to the oxygen supply port. B: A capnometrytype oxygen mask is fitted like a normal face mask and can supply normal oxygen flow. Expiratory flow is drawn into the sidestream for measurement of end-tidal carbon dioxide concentration.

fusion mismatching. ${ }^{4,17}$ In this study, we focused on accuracy of $\mathrm{P}_{\mathrm{ETCO}_{2}}$ measurement using a capnometry-type oxygen mask in subjects without a past medical history of pulmonary disease.

The capnometer was calibrated before oxygen administration. Immediately after admission to the ICU, oxygen at $6 \mathrm{~L} / \mathrm{min}$ was administered via an adult-size capnometrytype oxygen mask. The capnometry mask was positioned such that the bedside monitor displayed a normally shaped capnography waveform and a normal $\mathrm{P}_{\mathrm{ETCO}_{2}}$ value. The $\mathrm{P}_{\mathrm{ETCO}_{2}}$ was measured with a sidestream capnometer by spectrophotometry.

A blood sample for blood gas analysis was obtained from an artery before measurement of $\mathrm{P}_{\mathrm{ETCO}_{2}}$. After blood gas analysis, $\mathrm{P}_{\mathrm{ETCO}}$ under the resting condition was measured using the capnometry-type oxygen mask; next, the subject was encouraged to take a few deep breaths, and $\mathrm{P}_{\mathrm{ETCO}_{2}}$ under the deep-breathing condition was measured using the same device. Blood gas analysis and $\mathrm{P}_{\mathrm{ETCO}_{2}}$ measurement were performed after a constant and normally shaped capnography waveform was confirmed after 30 min of oxygen administration.

Subjects who had episodes of apnea, dyspnea, and arterial desaturation (defined as $\mathrm{S}_{\mathrm{pO}_{2}}<95 \%$ ) were eliminated from this study. The study period was $30 \mathrm{~min}$ for each subject.

\section{Statistics}

Quantitative variables are expressed as median and interquartile range. The relationship between $\mathrm{P}_{\mathrm{ETCO}_{2}}$ and $\mathrm{P}_{\mathrm{aCO}}$ was analyzed by the Pearson product moment correlation coefficient for assessing validity and reliability. Because a few measurements were obtained for each subject, the mean bias and limits of agreement were estimated
Table 1. Demographic and Perioperative Characteristics of Subjects

\begin{tabular}{lc}
\hline \hline \multicolumn{1}{c}{ Characteristics } & Subjects $(N=25)$ \\
\hline Male, $n(\%)$ & $15(60)$ \\
Age, median (IQR), y & $62(57-76)$ \\
Weight, median (IQR), kg & $59.7(53.0-68.6)$ \\
BMI, median (IQR), kg/m ${ }^{2}$ & $22(20-24)$ \\
Smoker, $n(\%)$ & $9(36)$ \\
COPD, $n(\%)$ & $4(17)$ \\
Anesthesia duration, median (IQR), h & $9.1(7.4-10.6)$ \\
Hepatic surgery, $n(\%)$ & $12(48)$ \\
Pancreatoduodenectomy, $n(\%)$ & $6(24)$ \\
Cholecystectomy, $n(\%)$ & $7(28)$ \\
Laparotomy, $n$ & 5 \\
& \\
IQR $=$ interquartile range & \\
BMI $=$ body mass index & \\
\hline
\end{tabular}

by a component of variance technique. ${ }^{18}$ The agreement between $\mathrm{P}_{\mathrm{ETCO}}$ and $\mathrm{P}_{\mathrm{aCO}}$ was assessed using a BlandAltman plot. Dissociation between $\mathrm{P}_{\mathrm{ETCO}_{2}}$ and $\mathrm{P}_{\mathrm{aCO}}$ under 2 breathing conditions was compared by the Student $t$ test. For 2-tailed tests, $P<.05$ was considered statistically significant. Statistical analyses were performed with Prism 6 for Mac OS X 6.9b (GraphPad Software, San Diego, California).

Sample size was calculated based on power analysis performed with R 2.13.0 statistical software (R Foundation for Statistical Computing, Vienna, Austria), which showed that 20 samples were required for a 2 -sided test with a significance of 0.05 , power of 0.8 , and estimated correlation coefficient of 0.6. Therefore, 27 subjects were enrolled in this study, considering the imminent elimination of subjects.

\section{Results}

Twenty-seven adult subjects were enrolled, and 2 subjects were excluded because their body mass index was $>30 \mathrm{~kg} / \mathrm{m}^{2}$. The characteristics of the subjects are provided in Table 1.

The results show that the capnometry-type oxygen mask was well tolerated by all subjects. No episodes of apnea or arterial desaturation were experienced during the study period. The correlation between $\mathrm{P}_{\mathrm{ETCO}_{2}}$ and $\mathrm{P}_{\mathrm{aCO}}$ under resting and deep-breathing conditions was statistically significant (Fig. 2). Pearson correlation analysis provided the following results: $\mathrm{P}_{\mathrm{aCO}}$ versus resting $\mathrm{P}_{\mathrm{ETCO}_{2}}, \mathrm{r}=0.50$ (95\% CI $0.126-0.745, P=.01$ ); and $\mathrm{P}_{\mathrm{aCO}_{2}}$ versus deepbreathing $\mathrm{P}_{\mathrm{ETCO}_{2}}, \mathrm{r}=0.56(95 \%$ CI $0.205-0.787$, $P=.001)$.

The Bland-Altman plot shows the relationship between blood gas analysis and $\mathrm{P}_{\mathrm{ETCO}}$ for each subject (Fig. 3). The bias and limits of agreement were $-12.6(-20.6$ to 


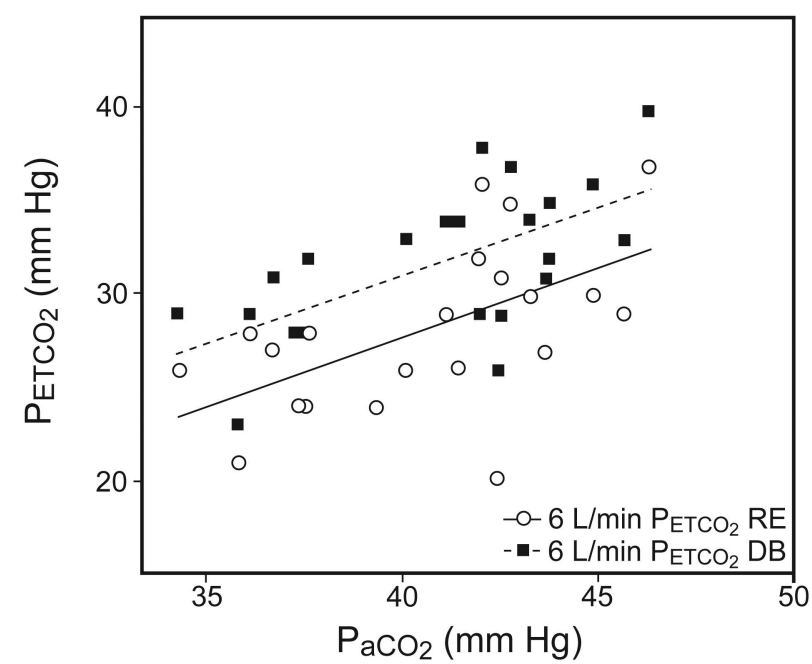

Fig. 2. Relationship between $\mathrm{P}_{\mathrm{acO}}$ and end-tidal carbon dioxide concentration $\left(\mathrm{P}_{\mathrm{ETCO}_{2}}\right)$ under resting (RE) and deep-breathing (DB) conditions. $\mathrm{P}_{\mathrm{ETCO}}$ and $\mathrm{P}_{\mathrm{aCO}}$ were statistically correlated $(r=0.50$ and 0.56 , respectively).

-4.6) for resting $\mathrm{P}_{\mathrm{ETCO}_{2}}$ and $-9.1(-16.1$ to -2.1$)$ for deep-breathing $\mathrm{P}_{\mathrm{ETCO}_{2}}$. The dissociation between deepbreathing $\mathrm{P}_{\mathrm{ETCO}_{2}}$ and $\mathrm{P}_{\mathrm{aCO}}$ was significantly smaller than that between resting $\mathrm{P}_{\mathrm{ETCO}_{2}}$ and $\mathrm{P}_{\mathrm{aCO}_{2}}(P=.002)$.

\section{Discussion}

To evaluate the use of a capnometry-type oxygen mask for continuous monitoring of $\mathrm{CO}_{2}$ in subjects extubated after abdominal surgery, we compared $\mathrm{P}_{\mathrm{ETCO}_{2}}$ measured by capnometry using the new capnometry-type oxygen mask with $\mathrm{P}_{\mathrm{aCO}_{2}}$ measured by blood gas analysis. We also compared the dissociation between $\mathrm{P}_{\mathrm{aCO}}$ and $\mathrm{P}_{\mathrm{ETCO}}$ under resting and deep-breathing conditions.

In our study, $\mathrm{P}_{\mathrm{aCO}}$ and $\mathrm{P}_{\mathrm{ETCO}}$, were significantly correlated under various breathing conditions (resting condition, $\mathrm{r}=0.50$; deep breathing, $\mathrm{r}=0.56$ ). Normally, dissociation between $\mathrm{P}_{\mathrm{aCO}}$ and $\mathrm{P}_{\mathrm{ETCO}_{2}}$ depends on the sum of space composed of apparatus, anatomical, and physiological dead space. In the postoperative situation, various factors affect dead space, leading to the dissociation between $\mathrm{P}_{\mathrm{aCO}_{2}}$ and $\mathrm{P}_{\mathrm{ETCO}_{2}}$. In our study, similar subjects with fewer respiratory complications were enrolled. Therefore, the sum of dead space was probably similar for all subjects, resulting in the statistically significant correlation between $\mathrm{P}_{\mathrm{aCO}_{2}}$ and $\mathrm{P}_{\text {ETCO }}$. However, the effect of other factors, such as comorbidity, skin incision, and postoperative pain, on postoperative respiratory function varied between subjects. These various perioperative conditions might affect a wide range of the limits of agreement. It was difficult to estimate the extent of dead space between subjects.

Statistically, the dissociation between $\mathrm{P}_{\mathrm{aCO}_{2}}$ and deepbreathing $\mathrm{P}_{\mathrm{ETCO}_{2}}$ was significantly smaller than that between $\mathrm{P}_{\mathrm{aCO}_{2}}$ and resting $\mathrm{P}_{\mathrm{ETCO}_{2}}(P=.002)$. We believe that the change in dissociation may be due to reduced ventilation/perfusion mismatching caused by a decrease in physiological dead space. Although continuous $\mathrm{CO}_{2}$ monitoring with deep-breathing $\mathrm{P}_{\mathrm{ETCO}_{2}}$ may be useful in clinical settings, it is difficult to predict the precise value of $\mathrm{P}_{\mathrm{aCO}_{2}}$ under the 2 breathing conditions. Because the limits of agreement have a wide range and are similar for both breathing patterns (16.0 [resting] vs 14.0 [deep breathing]), the bias of $\mathrm{P}_{\mathrm{aCO}}$ and $\mathrm{P}_{\mathrm{ETCO}_{2}}$ becomes smaller during deep breathing $(-12.6$ to -9.1$)$. Therefore, it is difficult to postulate which breathing pattern is superior for the
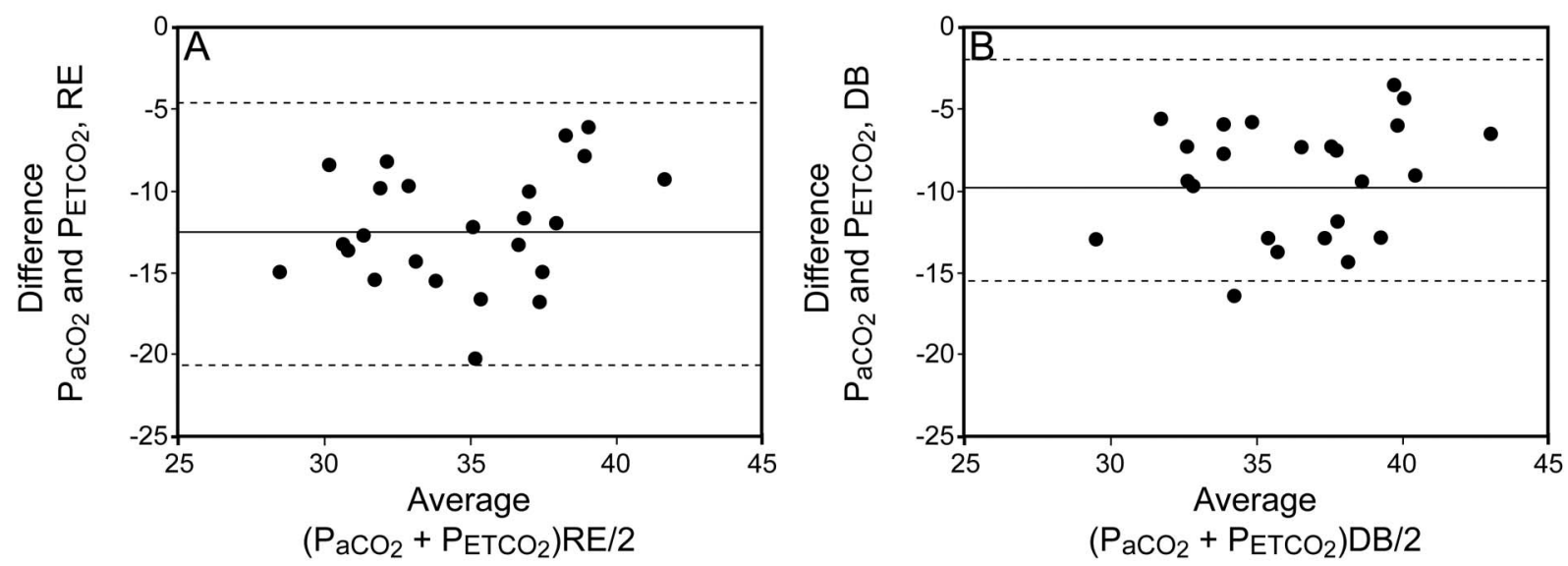

Fig. 3. A: The Bland-Altman plot shows differences in measurement of end-tidal carbon dioxide concentration $\left(\mathrm{P}_{\mathrm{ETCO}_{2}}\right)$ under the resting condition (RE) and $\mathrm{P}_{\mathrm{acO}_{2}}$ at $6 \mathrm{~L} / \mathrm{min}$. The bias and limits of agreement were $-12.6(-20.6$ to -4.6$)$. B: The Bland-Altman plot shows differences in measurement of $\mathrm{P}_{\mathrm{ETCO}}$ under the deep-breathing condition (DB) and $\mathrm{P}_{\mathrm{aCO}}$ at $6 \mathrm{~L} / \mathrm{min}$. The bias and limits of agreement were $-9.1(-16.1$ to -2.1$)$. 


\section{Oxygen Mask-Based Capnometry Device After Extubation}

prediction of $\mathrm{P}_{\mathrm{aCO}}$. Moreover, monitoring $\mathrm{P}_{\mathrm{ETCO}_{2}}$ may not be useful for evaluating the absolute value of $\mathrm{P}_{\mathrm{aCO}}$; however, it may be useful for assessing the $\mathrm{P}_{\mathrm{aCO}}$ trend.

In extubated subjects after general anesthesia, continuous monitoring of $\mathrm{CO}_{2}$ using the capnometry-type oxygen mask correlated with $\mathrm{P}_{\mathrm{aCO}}$, especially under the deepbreathing condition. Continuous capnometric monitoring previously required the patient to be intubated; therefore, its use was limited mostly to ventilated patients. A nasal cannula and face mask have been developed to monitor spontaneous breathing patterns in subjects requiring supplemental oxygen. ${ }^{11-13,19,20}$ However, a nasal cannula carries the risk of leakage if a patient exhales $\mathrm{CO}_{2}$ through the mouth. The accuracy of $\mathrm{CO}_{2}$ monitoring by a capnometer has been described; however, the relationship between $\mathrm{P}_{\mathrm{ETCO}_{2}}$ under the deep-breathing condition and $\mathrm{P}_{\mathrm{aCO}}$ has not been elucidated.

Continuous monitoring of $\mathrm{P}_{\mathrm{ETCO}}$ is useful for arterial $\mathrm{CO}_{2}$ assessment, particularly in patients with normal ventilation/perfusion relationships. ${ }^{5}$ However, in cases of impaired ventilation/perfusion relationships, such as postabdominal operations, $\mathrm{P}_{\mathrm{ETCO}_{2}}$ monitoring for arterial $\mathrm{CO}_{2}$ assessment is equivocal.

When patients resort to mouth breathing after extubation, nasal devices do not work. However, the capnometrytype oxygen mask samples expired $\mathrm{CO}_{2}$ from both the nose and mouth, reducing the risk of false alarms. However, this mask also carries the risk of rebreathing that is exacerbated by high breathing rates and use of long sampling catheters. ${ }^{21,22}$ Because the risk of rebreathing $\mathrm{CO}_{2}$ during oxygen delivery at a low rate has not been evaluated, it seems advisable to reserve this device for patients who require a supplemental oxygen flow conventionally used for oxygen face masks ( $>5 \mathrm{~L} / \mathrm{min}$ ). In our study, the oxygen supplementation rate was $6 \mathrm{~L} / \mathrm{min}$, which minimized the risk of $\mathrm{CO}_{2}$ rebreathing and is probably why none of the subjects developed $\mathrm{CO}_{2}$ retention.

This study has several limitations. First, the sample size was small (25 subjects), and subjects who underwent open upper abdominal surgery or laparotomy were included. These diverse operation methods lead to varying extents of postoperative pain and respiratory muscle dysfunction. Functional disruption of respiratory muscles by incision, even after surgical repair, may impair their effectiveness. Furthermore, postoperative pain may limit respiratory motion and influence $\mathrm{CO}_{2}$ production. Therefore, the usefulness of the capnometry-type oxygen mask in other conditions remains unclear. Second, smokers and subjects with COPD were enrolled in this study. However, previous studies on $\mathrm{P}_{\mathrm{ETCO}_{2}}$ monitoring showed limited accuracy in both intubated and non-intubated subjects with pulmonary disease. ${ }^{23,24}$ These comorbidities may affect pulmonary mechanisms after extubation. Third, data collection was not blinded, which may have affected $\mathrm{P}_{\mathrm{ETCO}_{2}}$ measurement under the deep-breathing condition. This relates to our conclusion that deep breathing elevates $\mathrm{P}_{\mathrm{ETCO}}$ due to reduction of ventilation/perfusion mismatching. However, in a few subjects, $\mathrm{P}_{\mathrm{ETCO}_{2}}$ decreased after deep breathing compared with that under the resting condition. The $\mathrm{P}_{\mathrm{ETCO}_{2}}$ was measured only twice by blood gas analysis. Therefore, it was difficult to confirm the usefulness of this device for continuous respiratory monitoring.

\section{Conclusions}

Further studies should be undertaken on continuous monitoring of $\mathrm{P}_{\mathrm{ETCO}}$ during the entire postoperative period using this device following similar surgeries with similar pulmonary conditions. In summary, our study shows that it is possible to measure the $\mathrm{P}_{\mathrm{ETCO}}$ under varying breathing conditions with the capnometry-type oxygen mask in subjects receiving oxygen supplementation after extubation following upper abdominal surgery to determine whether they are properly ventilating.

\section{REFERENCES}

1. Anderson CT, Breen PH. Carbon dioxide kinetics and capnography during critical care. Crit Care 2000;4(4):207-215.

2. Haldane JS, Meakins JC, Priestley JG. The effects of shallow breathing. J Physiol 1919;52(6):433-453.

3. Beecher HK. Effect of laparotomy on lung volume. Demonstration of a new type of pulmonary collapse. J Clin Invest 1933;12(4):651658.

4. Warner DO. Preventing postoperative pulmonary complications: the role of the anesthesiologist. Anesthesiology 2000;92(5):1467-1472.

5. Ahrens T, Sona C. Capnography application in acute and critical care. AACN Clin Issues 2003;14(2):123-132.

6. Sharma SK, McGuire GP, Cruise CJ. Stability of the arterial to end-tidal carbon dioxide difference during anaesthesia for prolonged neurosurgical procedures. Can J Anesth 1995;42(6):498-503.

7. Palmon SC, Liu M, Moore LE, Kirsch JR. Capnography facilitates tight control of ventilation during transport. Crit Care Med 1996; 24(4):608-611

8. Cook D, Meade M, Guyatt G, Butler R, Aldawood A, Epstein S. Trials of miscellaneous interventions to wean from mechanical ventilation. Chest 2001;120(6 Suppl):438S-444S.

9. Lumb, AB. Nunn's applied respiratory physiology, 6th edition. New York: Elsevier; 2005.

10. Liu S, Carpenter RL, Neal JM. Epidural anesthesia and analgesia. Their role in postoperative outcome. Anesthesiology 1995;82(6): 1474-1506.

11. Yanagidate F, Dohi S. Modified nasal cannula for simultaneous oxygen delivery and end-tidal $\mathrm{CO}_{2}$ monitoring during spontaneous breathing. Eur J Anaesthesiol 2006;23(3):257-260.

12. Paul J, Ling E, Hajgato J, McDonald L. Both the OxyArm and Capnoxygen mask provide clinically useful capnographic monitoring capability in volunteers. Can J Anaesth 2003;50(2):137-142.

13. Soto RG, Fu ES, Vila H Jr, Miguel RV. Capnography accurately detects apnea during monitored anesthesia care. Anesth Analg 2004; 99(2):379-382

14. Gaucher A, Frasca D, Mimoz O, Debaene B. Accuracy of respiratory rate monitoring by capnometry using the Capnomask in extubated 


\section{Oxygen Mask-Based Capnometry Device After Extubation}

subjects receiving supplemental oxygen after surgery. Br J Anaesth 2012;108(2):316-320.

15. Sesay M, Tauzin-Fin P, Verdonck O, Svartz L, Maurette P. Clinical evaluation of the Capnomask in the supine vs. prone position during monitored anaesthesia care. Eur J Anaesthesiol 2008;25(9): 769-771.

16. McKeague H, Cunningham AJ. Postoperative respiratory dysfunction: is the site of surgery crucial? Br J Anaesth 1997;79(4):415-416.

17. Griffin J, Terry BE, Burton RK, Ray TL, Keller BP, Landrum AL, Johnson JO, Tobias JD. Comparison of end-tidal and transcutaneous measures of carbon dioxide during general anaesthesia in severely obese adults. Br J Anaesth 2003;91(4):498-501.

18. Bland JM, Altman DG. Measuring agreement in method comparison studies. Stat Methods Med Res 1999;8(2):135-160.

19. Yazigi A, Zeeni C, Richa F, Chalhoub V, Sleilaty G, Noun R. The accuracy of non-invasive nasal capnography in morbidly obese sub- jects after bariatric surgery. Middle East J Anesthesiol 2007;19(3): 483-494.

20. Bongard F, Wu Y, Lee TS, Klein S. Capnographic monitoring of extubated postoperative patients. J Invest Surg 1994;7(3):259-264.

21. Doyle DJ. Time constant-related capnograph distortion: a theoretical analysis. J Biomed Eng 1991;13(6):500-502.

22. Breen PH, Mazumdar B, Skinner SC. Capnometer transport delay: measurement and clinical implications. Anesth Analg 1994;78(3): 584-586.

23. Yamanaka MK, Sue DY. Comparison of arterial-end-tidal $\mathrm{PCO}_{2}$ difference and dead space/tidal volume ratio in respiratory failure. Chest 1987;92(5):832-835.

24. Plewa MC, Sikora S, Engoren M, Tome D, Thomas J, Deuster A. Evaluation of capnography in nonintubated emergency department subjects with respiratory distress. Acad Emerg Med 1995;2(10):901918 